Military Technical College Kobry El-Kobbah, Cairo, Egypt

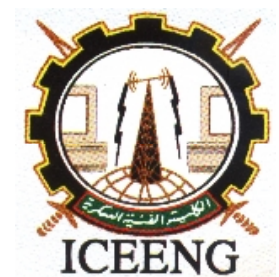

\section{$7^{\text {th }}$ International Conference on Electrical Engineering ICEENG 2010}

\title{
Electromagnetic Pollution in Buildings and Its Effects on Human Health
}

$$
\text { By }
$$

Korur Saim*

Korkmaz Serra Zerrin *

Sayın Selçuk*

\section{Abstract:}

The use of electrical devices has been increasing day by day as a result of growing industrialisation and improving economic conditions. Thus, all living creatures are being influenced to a great degree by electromagnetic pollution. In this study, the negative effects of electromagnetic fields, whose damages haven't been comprehended fully and have been ignored, on human health have been determined as a problem and some suggestions have been made to prevent electromagnetic pollution especially in buildings.

\section{Keywords:}

Electromagnetic field, electromagnetic pollution in buildings, human health

* Faculty of Engineering and Architecture, Selcuk University, Konya, Turkey 


\section{Introduction:}

The consumption of electrical energy has been increasing more and more in today's world depending on the development of industrialization and technology. As a result, the environment has been subjected to electromagnetic pollution. Because of the fact that it is invisible and its effects don't occur immediately; electromagnetic pollution hasn't been attached considerable importance when compared to other types of environmental pollution [1].

All the electrical devices produce electromagnetic fields depending on the amount of voltage and current they use. However base stations and energy transmission lines cause more pollution than the devices used in daily life.

As a result of irregular urbanization and unplanned structuring, high-voltage energy transmission lines and substations are in close proximity in big cities and people living in those dwellings are subjected to electromagnetic fields. The biological effects of electromagnetic pollution have been searched by scientists in various countries during the last thirty years and some findings about the effects of electromagnetic pollution especially on cancer cases have been gained. Although studies carried out haven't produced certain results, some standards have been set about electromagnetic fields in developed countries in the light of findings gained.

\section{Electromagnetic Field and Its Effects on Human Health}

A stationary electric charge produces an electric field surrounding space. But, if the charge is moving, a magnetic field is produced as well as an electric field. Electric and magnetic fields are characterized by their wavelengths and frequencies and the magnitude of the energy these fields have, changes according to the wavelength and frequency of the field [2]. Electromagnetic field is produced when electric and magnetic waves move perpendicularly to each other.For electromagnetic field to be generated, an accelerated electric charge is required. Magnetic field occurs wherever there is electric field and vice versa. While electric fields can be shielded or weakened by several materials, magnetic field can pass through various materials. That's why; the examination of the effects of electromagnetic fields on human health concentrates on the magnetic field [3]. Electromagnetic field affects living organisms in both positive and negative ways. Studies on this subject are carried out on cell and animal models in clinical environments.

\section{The Positive Effects of Electromagnetic Field}

The coherence between humanbeings' own magnetic field and the Earth's magnetic field may break down for several reasons. This is caused by the magnitude of the magnetic field that dwellings have. All the fields have three variables: frequency, the direction of spin and the magnitude or power of spin. Human body supports its own energy when these variables adapt to human body, and this magnetic interaction 
provides exchange of substances in cell membranes [4].

According to scientists, magnetic field deficiency in human body causes such disorders as fatigue and headache. These kinds of health problems can be treated providing magnetic fields to the outside of the body by means of electromagnetic waves. This is called "Magnetotherapy Treatment" [5]. As well as being benefitted from in medicine, high-frequency electromagnetic waves are used in various industrial applications i.e. food industry, textile industry and more importantly in defence industry. Knowing the effects of biomagnetic field on extraterrestrial factors and immediate surroundings is of great importance to take precautions and treatment.

\section{Negative Effects of Electromagnetic Field}

In addition to its positive effects, electromagnetic fields with very different frequencies and wavelengths have several negative effects on living beings.

All the biological appearances are electrical on Earth.The creation and conservation of plants, animals and humans are directed by radiation reactions in the atmosphere and biosphere. All living organisms have adapted to electric, magnetic and electromagnetic fields throughout their creation and development processes and maintained their life with these fields in a balanced way [6]. However, the balance of these fields has also been disturbed likewise many other fields and as a result, electromagnetic pollution has begun to pervade especially big cities and the Earth (Photo 1).

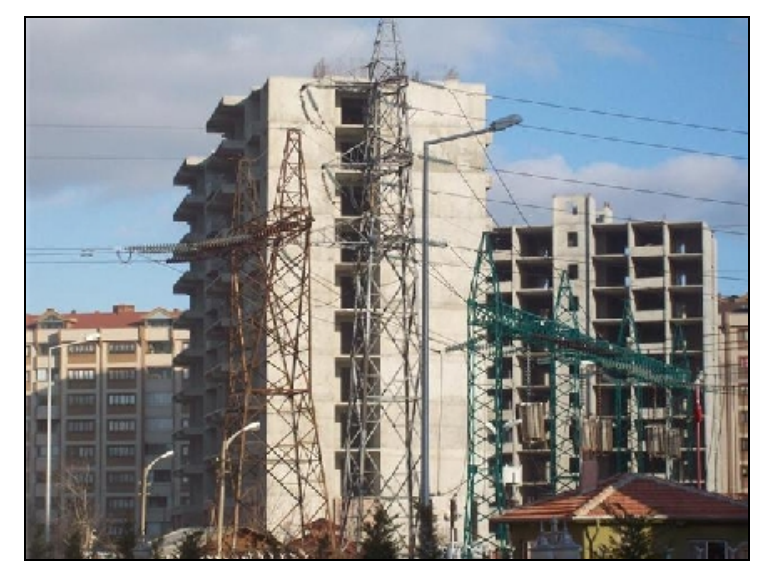

(a)

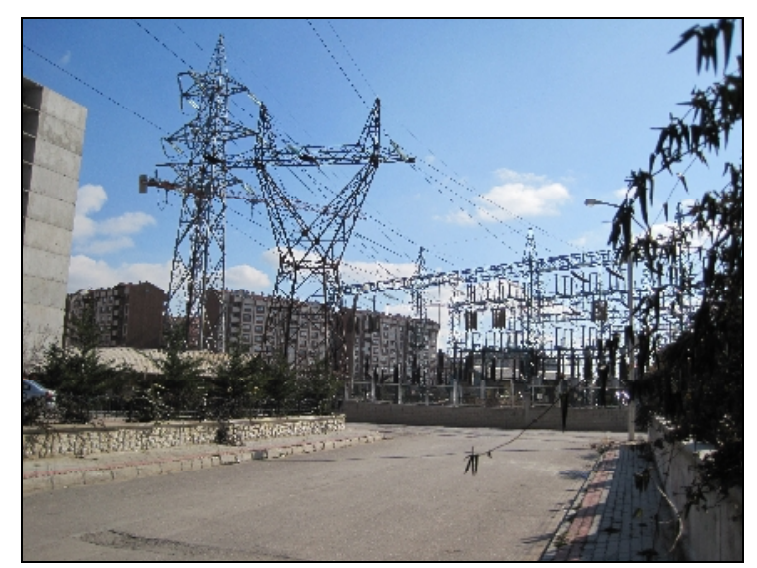

(b)

Photo 1. Switchyards in residential areas [Archive of Korkmaz]

The living beings influenced by the effects of electromagnetic fields absorb the energy of these fields. Thus, it causes changes in the electric currents of some organs and temperature increase in the body. Moreover, electromagnetic radiation damages the chemical structure of histoblasts [7]. Scientific studies conducted has shown that electromagnetic fields cause some types of cancers, neurological disorders (e.g. (ALS, Alzheimer disease), disease-like symptoms (e.g., dizziness, headache, 
insomnia), depression, suicide attemps, reproductive system problems and spontaneous abortion [8].

The effects of electromagnetic pollution has been searched by scientists in various countries from time to time and it has been seen that from children who live in the same neighbourhood, those who live nearby the power lines are more likely to catch cancer rather than others [9].

Some standards have been developed about electromagnetic fields in developed countries as a result of the findings gained from studies carried out.

The permitted amount of electromagnetic field in environments where dwellings are situated, the time of occupational exposure to high levels of electromagnetic fields and activities based on the amount of electromagnetic field in energy tranmission lines are restricted by these standards.

\section{Electromagnetic Pollution in Buildings}

One of the phenomenons affecting the buildings and the physical environment is pollution. Pollution is defined as the accumulation of contaminants that cause instability, disorder, harm or discomfort to the ecosystem i.e. physical systems or living organisms [10].

When contaminants arising from natural and artificial electrical generations that occur indoors or outdoors disturb the natural balance and order, it is called "Electromagnetic Pollution". For an electromagnetic generation to cause pollution, it is to go beyond the normal level in nature and affect the health of living beings negatively [11].

The electromagnetic pollution that influences the lives and health of people sneakily can be examined under the following headings :

a) outdoor electromagnetic pollution

b) indoor electromagnetic pollution

\section{Outdoor Electromagnetic Pollution}

Outdoor electromagnetic pollution can be grouped under two headings: natural and artificial electromagnetic pollution. Natural electromagnetic pollution is caused by some generations occuring in the atmosphere and underground.Electric fields with variable intensity and frequency, static electric and magnetic fields (i.e. thunderbolt), type and density of natural ions in the air can be shown as examples of electromagnetic generations in outdoors [12].

Electromagnetic pollution outside the buildings arises from electrical systems. These systems include electrical generators (i.e. generators), high-voltage lines, transmission and switchyards (Photo 2), transformators, base stations and lowvoltage (220-380 V) lines. 


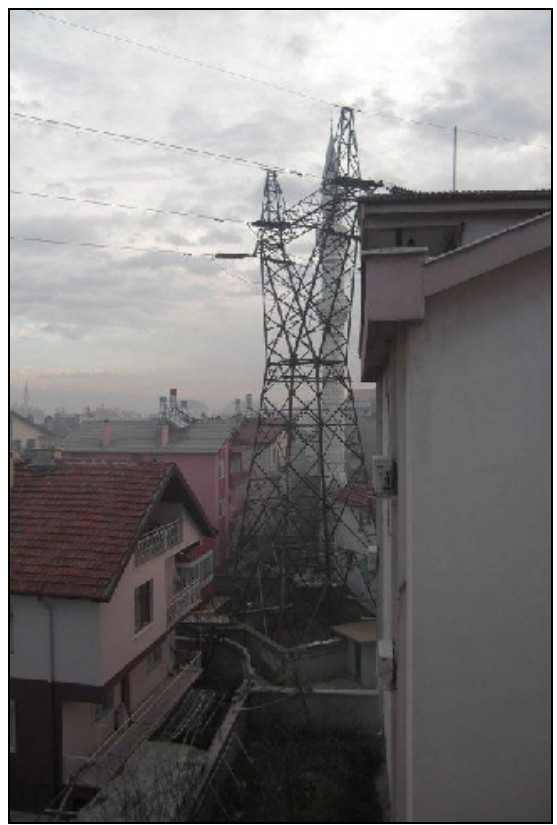

(a)

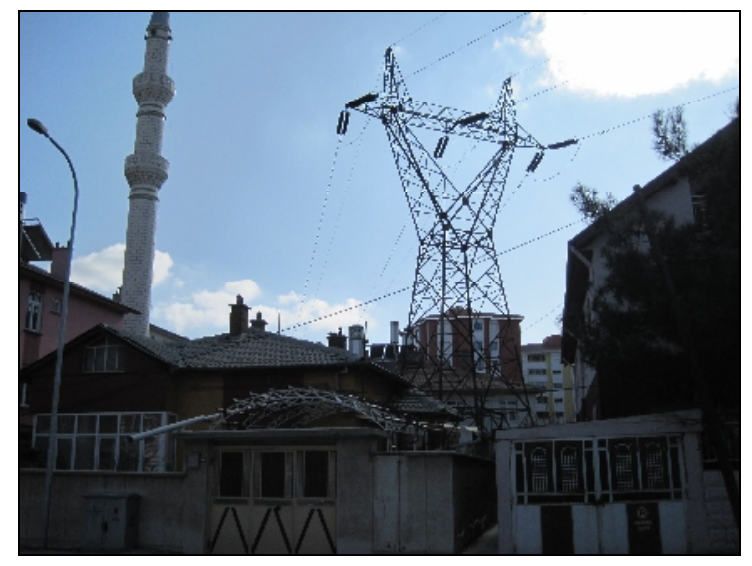

(b)

Photo 2. High tension lines in residential areas [Archive of Korkmaz]

In the immediate environment of high-voltage lines and substations, alternative magnetic fields occur. The more one goes away from high-voltage lines, the more the amount of electric and magnetic field decreases. People living in dwellings located on transformers (Photo 3) and on which base station is settle down (Photo 4) are influenced by electromagnetic fields every hour and according to the studies made, it has been observed that serious health problems are seen in people who do not live at least $10 \mathrm{~m}$. away from electricity substations [13].

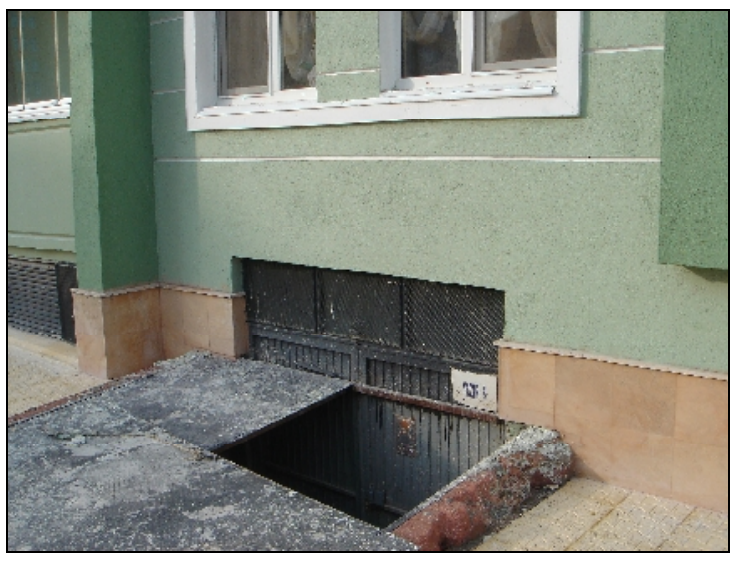

Photo 3. Residential building based on transformer station [Archive of Korur]

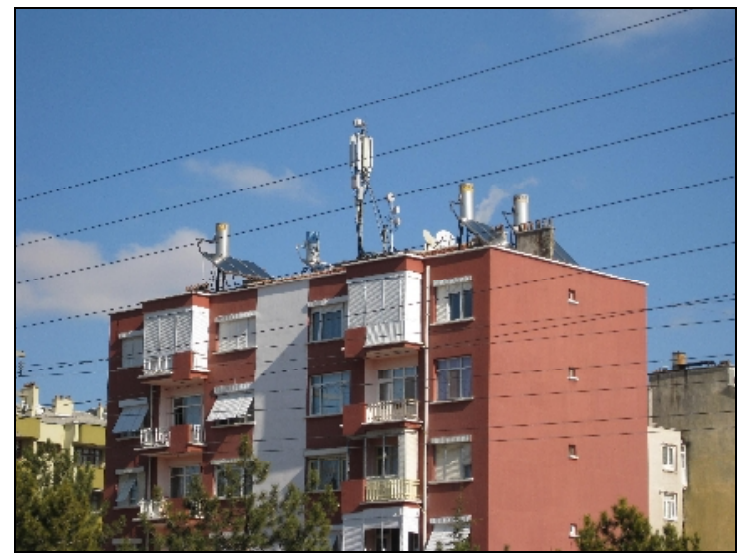

Photo 4. Residential building which base station is located on [Archive of Korkmaz] 


\section{Indoor Electromagnetic Pollution}

Indoor electromagnetic pollution has natural and artificial sources. While natural electromagnetic pollution sources are building products and materials constituting them, artificial sources are electrical systems in buildings [12].

Natural electric and magnetic fields affecting the inner side of buildings are caused by some building products. These are petrol-derivated artificial building products with high density and electrical resistance i.e. synthetic carpets, tiles and plastic wall panels. When positive and negative ions accumulate on building products, electrostatic discharge occurs. Thus, upsetting the balance of ions in the air, it affects human health in a negative way.In addition, building products consisting of iron and alloys in the shape of pipes and tubes such as natural gas, water and heating system pipelines, iron reinforced-concrete equipments, anchorage fields etc. cause natural electromagnetic pollution [12].

Artifical electromagnetic pollution inside buildings is caused by alternative energy, magnetic and electromagnetic fields produced by electrical systems. Electric field intensity occurs to some degree around any inactive or standby electrical system [7].

Although wires inside the walls draw less attention among the low-frequeny magnetic field sources, they are very important in creating such fields.

Electric equipments which are made according to right installation principles produce lower magnetic fields. However, these principles aren't taken into consideration in many buildings and a density of cables can be seen especially in the installation shafts of multi-storey buildings and under raised-floors. That's why such floors are built unnecessarily [14].

In electrical installation order, electricity cables close to the head level of a person affect neural system negatively. In electrical installation, electric currents passing through all circuits accumulate in conduit lines and as a result, high magnetic field intensity occurs around the distribution and fuse board and conduit lines [13].

The most important electromagnetic pollution sources indoors are devices working by electical systems (i.e. hair-dryer, razor, microwave oven, television, computer, etc.) and the fields that extension cables generate.

Electromagnetic pollution caused by electrical systems outdoors may get into the buildings by means of building products that have high electrical and magnetic conductivity. If natural gas and water transmission lines meet electrical systems, an artificial electromagnetic field can be produced and the inner sides of the building may be influenced by this situation. Moreover, if the vertical and horizontal pipelines of a heating system are close to the trunk cable, electromagnetic pollution can be carried in the whole heating system [12].

The surface of fiberglass tiles, which are used in the roofs of buildings, is made up of aluminium foils and it can be influenced by electromagnetic field caused by high or low voltage lines nearby. Aluminium tiles will be able to affect electromagnetic air by working like an antenna [13]. 


\section{Conclusions:}

While humanbeings put up defences against physical hazards that they can perceive with their five senses, they can not do the same thing against the effects of mentioned fields that have been increasing rapidly day by day as they are imperceptible. The effects of electromagnetic fields can be seen on the increased risk of heart attacks even at the age of 20, the collapse of immune systems, tendency to diseases, increases in brain haemorrhage and cancer rates. Research carried out so far has shown that it is not quite possible to avoid from the effects of EM fields in the modern world. However, the amount of these fields and the exposure time of people to such fields can be reduced considerably without high costs.

Each kind of electricity causes electromagnetic pollution according to its quality and quantity and eachvmagnetic pollution causes many different health problems for humanbeings. As eco-consciousness has gained more importance, protection ways from the effects of electromagnetic pollution also have. In this study, the correlation between electromagnetic pollution and human health and buildings has been established systematically. Precautions to be taken against electromagnetic pollution can be divided into three groups:

\section{CITY PLANNING PHASE}

- Outdoor precautions, building envelope precautions and indoor precautions.

- The degree of electromagnetic pollution influencing buildings in urban scales should be detected by local authorities and an electromagnetic pollution map of the region should be prepared by analyzing the data gained from measurements via CBS.

- Considering the map of electromagnetic pollution, facilities such as schools, hospitals, nurseries etc. and settlements should be established in areas well away from energy transmission lines, base stations and substations.

- In order to prevent the electromagnetic pollution, electricity substations should be grounded if existing buildings are close to them.

- Switchyards and high voltage lines should go underground in regions where irregular and unplanned urbanization grow. But, this method is not preferred because of expensive maintenance costs. Buildings with electrical systems should be protected by the application of masking method to the exterior of the buildings.

\section{BUILDING DESIGN PHASE}

- The blind facades of buildings or units such as water closets, bathrooms or stores that are not used so often should face the high voltage lines.

- Living beings, which can function as a shield against electromagnetic pollution such as trees that are ever-green, higher than buildings and have sap all seasons, should be used.

- High structures such as chimneys, towers, antennas etc. should be avoided from in buildings. High buildings should not be constructed in places where 
natural heights are not common. If available; lightning conductors should be placed at higher points for such kind of buildings.

- Copper, aluminium and iron tiles used for roofs, space frame systems, metal door and window joints should be grounded. Metal items consisting the base of a building should be connected to earth system.

- Lines that are installed from cutout boxes to main switchboards should be designed to be kept at a well distance from places that are used often and installation shafts and installation under wet areas such bathrooms, toilets etc. should be masked all around.

- Electric cables inside walls and drop ceilings should go through metal pipes and the whole system should be grounded.

- The balance of ions can be maintained by using cane and wooden products as well as clothes in the interior decoration of buildings. Chemical substances (i.e. polyester) that are used to add color or enhance the stability of natural building products disturb the balance of ions and that's why, they shouldn't be used. Instead of materials causing electrostatic charges such as plexiglass, rubber, PVC or metal, natural building products should be preferred. However, if metal-derivated materials are to be used for visuality and concept, then, these products should be grounded to prevent EM pollution.

\section{POST OCCUPANCY PHASE}

- During design process, the service tranmission lines of a building should be kept apart from each other and electrical installation should not be close to head level considering neural effects and should be grounded.

- Extension cables shouldn't be held for a long time and electrical devices should not stay plugged in. One should stay away from electrical devices as far as possible and devices that are held in close contact with human body such as razors or hairdryers should be used for short time.

- In addition to all these precautions, firms designing electrical products should ground all electrical devices or cover them with non-conductive materials in order to minimise their electromagnetic effects. The amount of electromagnetic waves that these devices send out should be explained to users clearly.

We had better be aware of the fact that if necessary precautions aren't taken against electromagnetic pollution, the effects of electromagnetic radiation we are exposed to will increase day by day and more serious disorders will be seen in humanbeings.

\section{References:}

[1] S. Şeker, O. Çerezci, Radyasyon Kuşatması, Boğaziçi University Printing, stanbul, 2000.

[2] D. J. Griffiths, Electromagnetic Theory, 2 nd Edition, Turkish Translation: Bekir Karaoğlu, Bilgi Tek Printing, stanbul, 1996.

[3] Web Address: http://consumerlawpage.com 
[4] E. Önal, Elektromanyetik Alanların Canlı Organizmalara Etkilerinin ncelenmesi, nönü University, Institute of Science, MA thesis, Malatya, 2005.

[5] Web Address: http://www.chemnmr.colorado.edu/ammrl/archives/September98/0025.html (S. Chandrasekaran, 1998.)

[6] A. Akman, Yapılarda Elektriğin nsan Sağllŭg Üzerindeki Etkileri, YEM Printing, Yap1 dergisi, V. 183, P. 100-102, stanbul, 1997.

[7] S. Şeker, O. Çerezci, Elektromanyetik Alanların Biyolojik Etkileri Güvenlik Standartları ve Korunma Yöntemleri, Boğaziçi University Printing, stanbul, 1991.

[8] M. Feychting, A. Ahlbam, Magnetic fields and cancer in children residing near Sqedish high-voltage power lines, American Journal of Epidemiology, V. 138, N. 7, P. 467-481, United States, 1997.

[9] W. F. Horton, S. Goldberg, Power Frequency Magnetic Fields And Public Health, CRC Pres, Florida, USA, 1995.

[10] A. Öztürk, Yapı çi Kirliliği ve nsan Sağglı̆̆ına Etkisi, Unpublished Doctoral Dissertation, Yıldız University, stanbul, 1988.

[11] F. Kur, Wohngrifte Einleitung , Eichborn Verlag, P. 20-38, Frangfurt, 1993.

[12] A. H. Topar, Yapıda Elektroiklimsel Kirlilik ile nsan Să̆lı̆̆ lişkisi ve Alınabilecek Önlemler, Y1ldız Teknik Universtiy, Institute of Sciences, MA Thesis, stanbul, 1996.

[13] D. W. Rose, Elektrosmog - Elktrostress, Kipenheuer+Witchs Verlag, Köln, 1994.

[14] H. Özaktaş, Günlük Hayatta Karşılaşılan Elektromanyetik Alanlar ve nsan Sa $\breve{g} l$ ğ $l$, Bilişim Toplumuna Giderken Elektromanyetik Kirlilik Etkileri Sempozyumu, Ankara, 1999. 